\title{
Active Ageing Index (2016-18): Addressing a Long-Standing Strategic Policy Aim
}

\author{
Sarah Harper ${ }^{1}$ \\ Published online: 3 November 2020 \\ (C) Springer Nature B.V. 2020
}

We are delighted again to publish key papers from the work with the Active Ageing Index (2016-18). Our support of this tool, sponsored by United Nations Economic Commission for Europe and the European Commission's Directorate General for Employment, Social Affairs and Inclusion, has endured a long relationship. As we described in our previous special edition on the AAI (JPA, 10, 2017), this emerged from a long-standing strategic policy aim expressed by the European Union (EU), United Nations and European Council to help promote and implement active ageing at regional (UNECE, European Union), national and local levels. As a result, the "Active Ageing Index" (AAI) was developed and launched in 2012, in collaboration with the European Centre for Social Welfare Policy and Research in Vienna and with the support of a multi-stakeholder expert group.

The AAI comprises twenty-two indicators grouped into four domains. The first three aim to capture experiences and achievements: employment; participation in society; and independent, healthy and secure living. The fourth - capacity and enabling environment for active ageing - quantifies the contextual conditions. In detail ${ }^{1}$ the indicators used for the first domain are the employment rate for four 5-year age groups, from 55 to 74 years. Indicators in the "participation in society" domain concern informal care provision (to children, grandchildren, but also to adults in need of care), voluntary activities and political participation. The third domain includes physical exercise, access to health services, being able to live independently, financial security, physical safety, and lifelong learning. The last domain is devoted to the capacity and enabling environment for active ageing, and considers aspects such as healthy life expectancy, mental well-being, internet use, active relations.

This second collection of papers were presented during the Second International Seminar on the Active Ageing Index in Bilbao in September $2018,{ }^{2}$ sponsored by the

\footnotetext{
${ }^{1}$ Active Ageing Index project. https://statswiki.unece.org/display/AAI/Active+Ageing+Index+Home ${ }^{2} \mathrm{http}: / /$ www.unece.org; https://www.ageing.ox.ac.uk/news/AAI-second-international-seminar
}

Sarah Harper

sarah.harper@ageing.ox.ac.uk

1 Oxford Institute of Population Ageing, University of Oxford, Oxford, UK 
UNECE, the European Commission's DG EMPL, the University of the Basque Country, and the Oxford Institute of Population Ageing, with the support of the Government of Biscay (Spain). The seminar brought together researchers, civil society representatives, policymakers and other stakeholders and provided a multidisciplinary forum for those interested in the use of AAI to enhance the knowledge about ageing and older people, and lead to the development of better policies. The best papers were selected for merit awards and publication.

The publication of these papers has been enhanced by a key analytical report from the UNECE / European Commission ${ }^{3}$ which provides an excellent framing to the study and is highly recommended. We here publish some of the key framework analytics to introduce this special edition. The report takes into account the different forms through which older persons contribute to society and economy, by means of paid or voluntary work, informal care, political participation, or by keeping healthy, informed and independent lifestyles even at an advanced age. It also considers environmental factors which enable them to be more active. The analysis of AAI results in relation to GDP per capita, income inequality (Gini index) and life satisfaction of older people highlighted a strong positive correlation between AAI scores, on the one hand, and GDP per capita and life satisfaction, on the other.

The report considers changing trends at EU level between 2008 and 2016, reporting that in this time the overall AAI score increased from 32.2 to 35.8 points for the EU average. This growth of roughly over $10 \%$ is the combined result of differentiated developments taking place in the 28 EU countries. When results are differentiated by gender, the increase in the overall AAI score for women over the 2008-2016 period exceeds that of men in most countries, with few exceptions: Austria, Hungary, Luxembourg, Malta, the Netherlands and Portugal). In addition, in three countries, Greece, Romania and Slovenia, there is actually negative development for men over this time.

The report usefully identifies four main groups of countries, each of them characterised by a particular set of active ageing policy challenges. The individual country scores achieved in each of the four AAI domains provided the basis to group countries into four clusters, characterised by similar situations in terms of domainspecific achievements and performances. This allowed the identification of core challenges affecting each cluster in a structured manner.

1. Green cluster: composed of Central European and Mediterranean Member States only, this cluster faces challenges across all domains, but especially in the area of social participation: Bulgaria, Croatia, Greece, Hungary, Italy, Poland, Romania, Slovakia, Slovenia and Spain.

2. Red cluster: spread across Continental Europe and Mediterranean islands, this group reports quite low employment rates in older age groups: Austria, Belgium, Cyprus, France, Luxembourg and Malta.

3. Blue cluster: symmetrically opposite to the red cluster, this more geographicallydispersed cluster generally reports below average scores in all domains except in that of employment: Czech Republic, Estonia, Germany, Ireland, Latvia, Lithuania and Portugal.

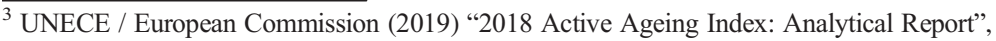


4. Yellow cluster: this "Nordic" cluster presents well above average results in three domains, and only slightly higher values in the domain of Independent living: Denmark, Finland, Sweden, Netherlands, and the United Kingdom - these latter two countries delighted (I am sure) to be renamed "Nordic".

The report concludes with suggestions which emerged from consultations after the first report $^{4}$ and the Second International Seminar 2018. It therefore recommends that future research has a stronger emphasis on the inequalities that could lead to the marginalisation of particularly vulnerable groups in our ageing societies. These include older persons characterised by socio-economic deprivation such as a lower educational level and income, those suffering from poorer health, belonging to ethnic minorities, or having a migration background. Another priority for strengthening empirical evidence for policymaking, they suggest, concerns the need to pay more attention to the oldest age groups by using more detailed, age-disaggregated AAI-related data, in order to avoid the trap of considering all older people as a homogeneous group. Policies to promote active ageing should, they argue, be based on comprehensive information explaining what it means to age at 65,75 or 85 , since good health and access to care for the oldest groups are often preconditions for remaining active in other fields. In addition to investing in age disaggregated data for AAI indicators, the use of cohort analysis and of longitudinal data to identify which life-course events and trajectories are likely to facilitate active ageing can be seen as another methodological challenge with which future AAI applications may have to deal.

In order to assist all researchers in the use of the AAI tool, guidelines on how to calculate the AAI in different contexts have now been made available a set of instructions (UNECE/ European Commission 2018). The underlying idea is to encourage users to learn about the tool, by experimenting with different weights for individual domains and indicators when building their "personalised AAI". This possibility, while conceptually building on the instrument's core multidimensional components, would allow users to take into account different cultural perspectives and policy priorities, and to adjust AAI calculations accordingly. They allow users to more easily understand how to proceed when data are lacking, but also on how to make the interpretation of AAI results clearer, its use easier, more flexible and transparent, and at the same time more appropriate to fit national or regional policy goals, by identifying the most suitable weighting methods. We strongly support this development.

This special edition of JPA comprises 5 papers which explore the different inputs the AAI may have to our understanding of ageing - policy, practice and empirical, at national, local and comparative levels.

Trends and Inequality in the New Active Ageing and Well-Being Index of the oldest old: A case study of Sweden focuses on the oldest old (75 years and older), combining the Active Ageing Index with the Nordic welfare research tradition. Creating a new Active Ageing-Well Being Index (AA-WB Index) the paper analyses the Swedish Panel Study of Living Conditions of the Oldest Old (SWEOLD) to consider the domains of inequality among this population.

\footnotetext{
$\overline{{ }^{4} \text { UNECE/European Commission }}$ (2015) Active Ageing Index 2014: Analytical Report.
} 
Employment of older people across Italian regions an exploration of drivers and barriers based on the Active Ageing Index aims to identify the main factors that contribute to strengthening the employability of aged people in Italy.

Is Active Ageing coping with population ageing? is a comparative exploration of the extent to which population ageing is affecting negatively active ageing indicators drawing on data from all EU countries in the AAI.

Active Ageing Index in Russia - Identifying Determinants for Inequality adapts the methodology of the AAI to individual-level data exploring the limitations of the approach. The high correlation of the index values with human capital indicators (health and education) underlines the importance of the early interventions aimed at promoting and supporting human capital at the earlier stages of the life course.

Extending the Active Ageing Index to Hong Kong Using a Mixed-Method Approach: Feasibility and Initial Results turns to move the AAi into a different cultural context. Drawing on qualitative interviews, the paper illustrates how the mixed-method approach could serve as an appropriate method in extending the active ageing research in the Asia-Pacific region.

Finally is a full example of how the AAI may be utilized at the regional level as we publish extracts from a recent report by Istat Produzione Editoriale Agosto 2020, Invecchiamento Attivo E Condizioni Di Vita Degli Anziani In Italia (Active Aging and Living Conditions of The Elderly in Italy). This report aims to draw attention to some elements worthy of consideration when developing the theme of active ageing at national and subnational level, arguing that we need to discard the idea that older adults are a burden for society, subjects in need of assistance, and use the AAI to embrace a different model, where older people are seen as vital subjects that can positively contribute to the community. They recognize that in Italy this issue has not yet acquired a central role in the public debate nor in the action of policy makers, despite the fact that the adoption of an approach centred on active ageing is globally considered a highly recommended innovation.

Recognising that the Active Ageing Index, like any composite indicator, is a simplification through which it is possible to highlight the social, economic, and cultural specificities of the different territorial realities that characterizes each country, they reveal how the AAI may offer a wealth of information and empirical evidence which may identify appropriate strategies to promote active ageing in different contexts. In particular, the authors argue that the AAI appropriately defined at regional level could turn into an excellent evaluation tool able to help policy makers define short- and long-term objectives and connect evaluations plans. This they present as a tool that contains the double function of monitoring and programming, working toward both individual and collective well-being.

Colleagues here at Oxford - Asghar Zaidi, Kenneth Howse and myself, have been delighted to work with the UNECE Population Unit together with the European Commission Directorate General for Employment, Social Affairs and Inclusion and the European Centre for Social Welfare Policy and Research on the AAI since 2012.

Publisher's Note Springer Nature remains neutral with regard to jurisdictional claims in published maps and institutional affiliations. 